\title{
Acanthochondria serrani sp. n. (Copepoda: Chondracanthidae) parasitic on Serranus auriga (Perciformes: Serranidae) from Argentinean waters
}

\author{
Paola E. Braicovich ${ }^{1,2}$ and Juan T. Timi ${ }^{1,2}$ \\ ${ }^{1}$ Laboratorio de Parasitología, Facultad de Ciencias Exactas y Naturales, Universidad Nacional de Mar del Plata, Funes 3350 , \\ (7600) Mar del Plata, Argentina; \\ ${ }^{2}$ Consejo Nacional de Investigaciones Científicas y Técnicas (CONICET)
}

\begin{abstract}
A new species of Acanthochondria Oakley, 1927 (Copepoda, Poecilostomatoida, Chondracanthidae), parasitic on Serranus auriga (Cuvier) from the Argentinean coastal zone, is described and illustrated. The new species differs from its congeners by the relative length of the neck and the protopod of leg 2. This is the second record of this genus for the South-eastern Atlantic and the first one from a serranid host.
\end{abstract}

Key words: parasitic copepods, marine fish, systematics, Argentina

Acanthochondria Oakley, 1927 is the largest genus of the family Chondracanthidae Edwards, 1840 (Østergaard et al. 2003). The latest review with a key to 43 valid species of this genus was given by Ho and Kim (1995). Four additional species were later described, A. kajika Ho et Kim, 1996, A. zebriae Ho, Kim et Kumar, 2000, A. hoi Kalman, 2003, and A. triangularis Alves, Luque et Paraguassú, 2003; the latter is at present the sole species recorded in the South-western Atlantic (Ho and Kim 1996, Ho et al. 2000, Alves et al. 2003, Kalman 2003).

As result of a parasitological study, a new species of Acanthochondria was found in the marine benthopelagic fish Serranus auriga (Cuvier) from Argentinean waters.

\section{MATERIALS AND METHODS}

A total of 89 specimens of $S$. auriga, captured off the Mar del Plata coast $\left(38^{\circ} 08^{\prime} \mathrm{S}, 57^{\circ} 32^{\prime} \mathrm{W}\right)$, were examined for parasitic copepods. The parasites were removed from branchial chambers, fixed, and stored in $70 \%$ ethanol; the appendages were dissected, cleared in lactic acid, and examined under a light microscope. Illustrations were made using a drawing tube. Measurements are given as the mean, followed by the range in parentheses. All measurements are in millimetres. The criteria for identifying the new species follow Ho and Kim (1995).

\section{RESULTS}

Acanthochondria serrani sp. n.

Figs. 1-26

Female (Figs. 1-15): Measurements based on 5 specimens. Body with slender head, elongate neck, and stout trunk. Total length 5.03 (4.74-5.21) (from anterior border of head, excluding antennules, to tip of posterior processes). Head devoid of processes, longer than wide, 0.90 (0.87-0.93) long and 0.69 (0.65-0.71) wide, and bearing median longitudinal sclerotized bar. Slender neck region formed by first and second pedigerous somites, 5 times longer than wide. Trunk stout, constricted at about midlength, 1.85 (1.50-2.11) long and 1.54 (1.33-1.90) wide and extended postero-laterally, forming two lobes, parallel to genito-abdomen (Figs. 1-3); posterior processes extending beyond distal limit of genito-abdomen. Genital complex conical, attached to postero-dorsal surface of trunk. Abdomen globular, small, broadly fused with genital complex, carrying pair of dorsal setules (Fig. 4). Caudal ramus with spinulated tip, probably representing fused caudal seta, and armed with 3 setae (1 dorsal and 2 ventral) (Fig. 5). Egg sacs cylindrical, multiseriate, 1.95 (1.71-2.17) long and $0.68(0.47-0.87)$ wide.

Antennule cylindrical, with 2 ventral spines on anterior margin and 3 subterminal setae and tipped with 8 naked setae ( 5 long and 3 short) and small knob (Fig. 6). Antenna 2 -segmented, terminal segment resembling recurved hook with striated ring near mid-length, without accessory antennule (Fig. 7). Labrum with fine spinules on posterior margin (Fig. 8). Terminal blade of mandible with 22-24 teeth on convex side and 20-23 smaller teeth on concave side (Fig. 9). Paragnath a small fleshy lobe armed distally with spinules (Fig. 10). Maxillule resembling small lobe tipped with 2 unequal setae (Fig. 11). Maxilla 2-segment-

Address for correspondence: P.E. Braicovich, Laboratorio de Parasitología, Facultad de Ciencias Exactas y Naturales, Universidad Nacional de Mar del Plata, Funes 3350, (7600) Mar del Plata, Argentina. Phone: +54 0223 475-4060; Fax: +54 0223 475-3150; E-mail: braicovi@mdp.edu.ar 


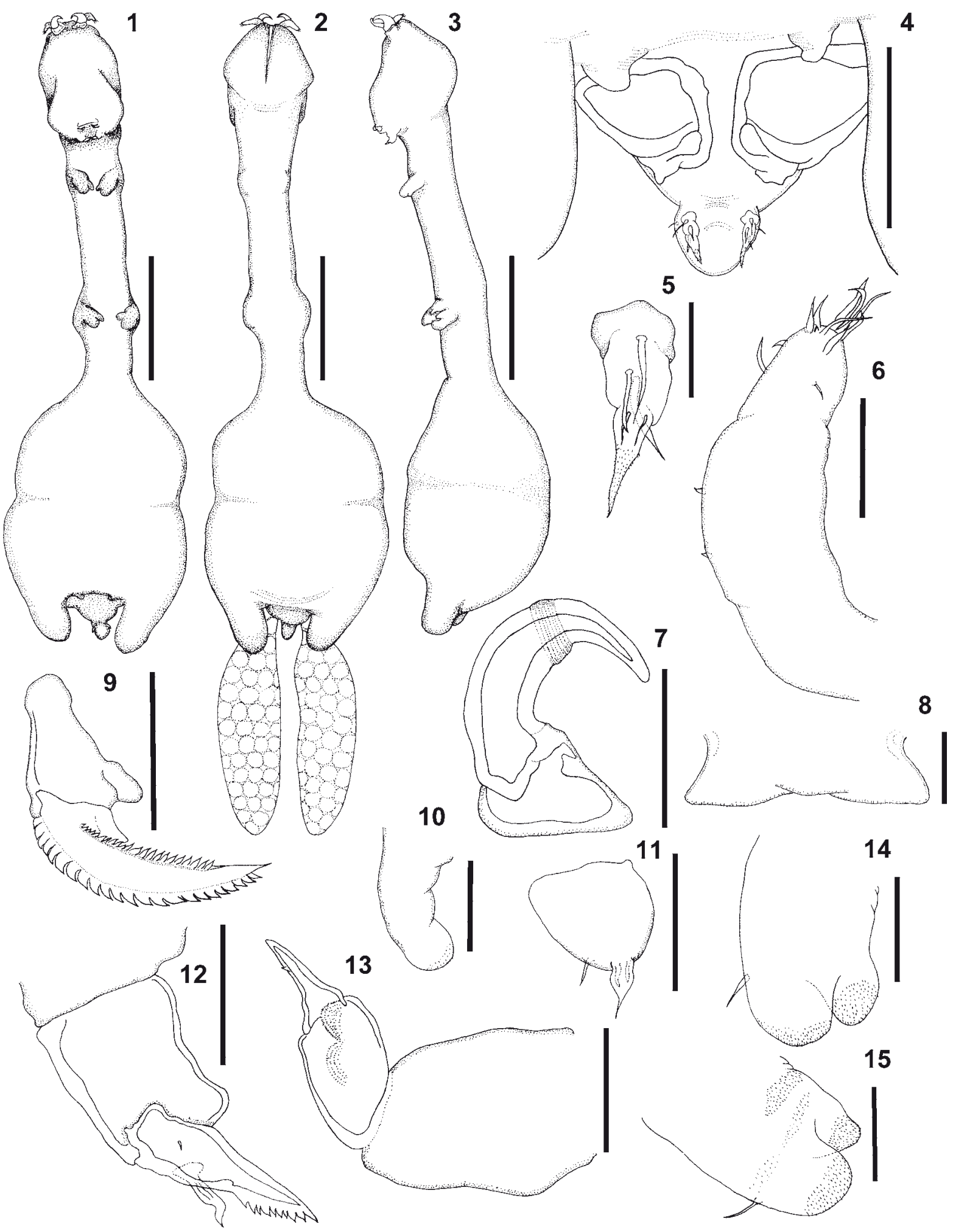

Figs. 1-15. Acanthochondria serrani sp. n., female. Fig. 1. Habitus, ventral view. Fig. 2. Habitus, dorsal view. Fig. 3. Habitus, lateral view. Fig. 4. Genito-abdomen, ventral view. Fig. 5. Caudal ramus, ventral view. Fig. 6. Antennule. Fig. 7. Antenna. Fig. 8. Labrum. Fig. 9. Mandible. Fig. 10. Paragnath. Fig. 11. Maxillule. Fig. 12. Maxilla. Fig. 13. Maxilliped. Fig. 14. Leg 1. Fig. 15. Leg 2. Scale bars: Figs. $1-3=1 \mathrm{~mm}$; Fig. $4=0.25 \mathrm{~mm}$; Fig. $5=0.03 \mathrm{~mm}$; Figs. $6,14,15=0.01 \mathrm{~mm}$; Figs. $7,9,11-13=0.05 \mathrm{~mm}$; Figs. $8,10=0.025 \mathrm{~mm}$. 


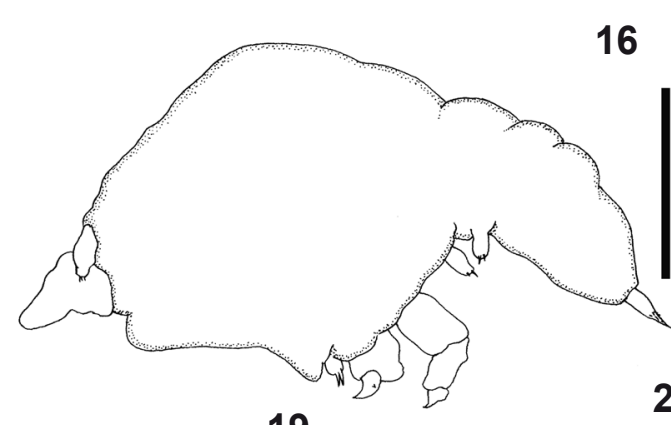

16

23

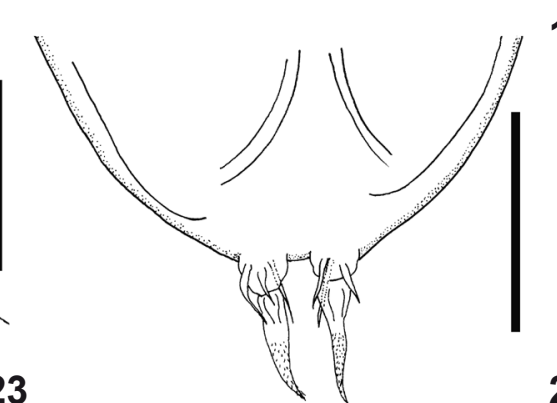

17

18
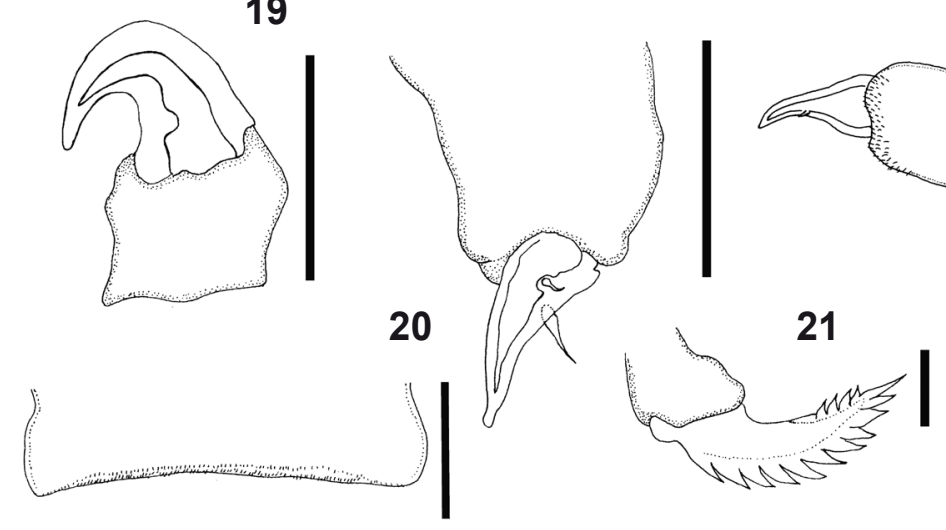

I

24

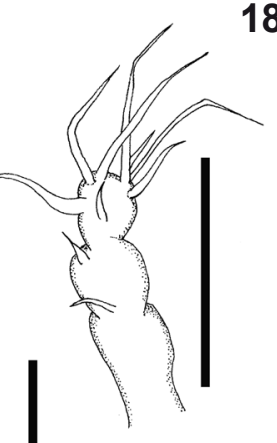

25
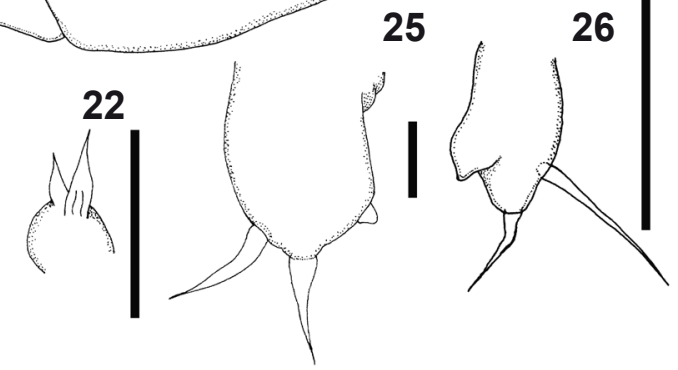

Figs. 16-26. Acanthochondria serrani sp. n., male. Fig. 16. Habitus, lateral view. Fig. 17. Genito-abdomen, ventral view. Fig. 18. Antennule. Fig. 19. Antenna. Fig. 20. Labrum. Fig. 21. Mandible. Fig. 22. Maxillule. Fig. 23. Maxilla. Fig. 24. Maxilliped. Fig. 25. Leg 1. Fig. 26. Leg 2. Scale bars: Figs. 16, 17, 19, $24=0.05$ mm; Figs. 18, 20, 22, $23=0.03$ mm; Figs. $21,25,26=0.01$ mm.

ed, first segment robust and unarmed, second segment armed with 2 setae at basal portion (one large and other small) and with row of 9 teeth on inner edge of terminal process (Fig. 12). Maxilliped 3-segmented, first segment robust and unarmed, second segment with lobate distal end bearing rows of spinules on inner edge, terminal segment small, claw-like with denticle at distal third of concave side (Fig. 13). Two pairs of biramous legs present. Leg 1 short, bilobed, situated on neck, short distance to head, protopod bearing outer seta; exopod larger than endopod; both with terminal patches of spinules (Fig. 14). Leg 2 with shorter basal portion, and ending in 2 rounded lobes; protopod with small outer seta, carrying rows of spinules, exopod longer than endopod; both with terminal spinules (Fig. 15). Legs 1 and 2 similar in length.

Male (Figs. 16-26): Measurements based on 5 specimens. Body $0.50(0.47-0.52)$ long and $0.22(0.20-0.25)$ wide; cephalothorax comprising more than half of total body length; metamerism of body indistinct (Fig. 16). Main body flexure located between second pedigerous somite and genito-abdomen. Genital complex with pair of ventral ridges marking margins of paired genital apertures (Fig. 17). Abdomen broadly fused with genital somite and indistinct. Caudal ramus pilose, armed with 3 naked setae (1 dorsal at base and 2 ventro-lateral).

Antennule small, with 3 lateral short setae, 1 subterminal long seta and tipped with 6 setae (4 long and 2 short)
(Fig. 18). Antenna 2-segmented, robust terminal segment uncinate without accessory antennule (Fig. 19). Labrum with denticles along posterior margin (Fig. 20). Terminal blade of mandible with 11 teeth along convex side and 4-5 smaller teeth on concave side (Fig. 21). Maxillule in form of naked small lobe bearing 2 elements (Fig. 22). Maxilla 2-segmented, first segment robust and unarmed, second segment armed with 2 setae (1 large and other small) at basal portion, and terminal process without teeth (Fig. 23). Maxilliped 3-segmented, first segment robust and unarmed, second segment with lobate distal end bearing spinules on inner edge, terminal segment a small claw with denticle on concave side (Fig. 24). Two pairs of reduced biramous legs present, both lobate; leg 1 (Fig. 25) with protopod bearing 1 outer seta. Exopod lobate, bearing 1 terminal seta; small endopod conical and unarmed. Leg 2 (Fig. 26) smaller than leg 1, with protopod bearing 1 outer seta. Exopod tipped with 1 seta.

Type host: Serranus auriga (Cuvier, 1829) (Actinopterygii, Serranidae).

Type locality: Mar del Plata coastal zone $\left(38^{\circ} 08^{\prime} \mathrm{S}\right.$, $\left.57^{\circ} 32^{\prime} \mathrm{W}\right)$, Argentina.

Date of collection: May-July and October 2007; January and March-June 2008.

Site of infection: Inner side of operculum.

Prevalence: $19 \%$ (17 fish infected of 89 examined).

Mean intensity: 1.2 . 
Material deposited: Holotype No. 26.209 (female), allotype No. 26.210 (male), and paratypes (2 females each with attached male) No. 26.211 are deposited in the Carcinological Collection of the Museo de La Plata (CHMLP), La Plata, Argentina. Two additional paratypes are deposited in the Institute of Parasitology, Academy of Sciences of the Czech Republic, České Budějovice, Czech Republic (Cat. No. Cr-10).

Etymology: The specific name is derived from the generic name of the fish host, Serranus auriga.

Remarks. By having the neck region longer than wide and consisting of first and second pedigers, female of the new species can be distinguished from most congeners included in the key provided by Ho and Kim (1995). Two of the remaining species, $A$. diastema Ho et Dojiri, 1988 and A. uranoscopi Ho et Kim, 1995, have a very long neck (at least 8 times longer than wide), whereas those with a moderately long neck, $A$. tchangi Yü, 1935, A . platycephali Heegaard, 1940 and A. inimici Yamaguti, 1939, differ from the new species by having leg 2 with an extremely long protopod (Type E sensu Ho and Kim 1995) (Ho and Kim 1995). Among the species described after Ho and Kim (1995), both A. zebriae and A. kajika have the neck region wider than long and consisting of first pediger only in A. zebriae, whereas it includes a narrow first pediger and a much wider second pediger in A. kajika (Ho and Kim 1996, Ho et al. 2000). Acanthochondria triangularis differs from the new species by having leg 2 with an extremely long protopod (Type E sensu Ho and Kim 1995) (Ho and Kim 1995, Alves et al. 2003) and A. hoi differs from the new species, as well as from all its congeners, by the combination of a Type B-V antennule and Type A leg 2 (Kalman 2003).

Male of the new species shows the characteristic features of the genus, which do not show species differences (Ho 1970), the exception being A. zebriae, with leg 2 missing and leg 1 reduced to a spiniform seta (Ho et al. 2000).

On the basis of the differences listed above, a new species, Acanthochondria serrani, is proposed. This discovery represents the second record of this genus for the South-eastern Atlantic and the first one from a serranid host.

Acknowledgements. The authors wish to thank Mr. Roberto Mazella and Mr. Hugo Mazella from the fish market Albatros, Mar del Plata, for kindly providing fish samples. The present study was funded by grants from CONICET (PIP No. 112200801-0024), ANPCYT (PICT No. 02199) and Universidad Nacional de Mar del Plata (EXA 442/08).

\section{REFERENCES}

Alves D.R., Luque J.L., Paraguassú A.R. 2003: Acanthochondria triangularis sp. nov. (Copepoda, Poecilostomatoida, Chondracanthidae) parasitic on Urophycis brasiliensis and U. mystaceus (Osteichthyes, Phycidae) from the Southern Brazilian coastal zone. Acta Parasitol. 48: 19-23.

DoJiri M., Ho J.S. 1988: Two species of Acanthochondria (Copepoda: Poecilostomatoida) parasitic on fishes of Japan. Rep. Sado Mar. Biol. Stn. Niigata Univ. 18: 47-56.

Ho J.S. 1970: Revision of the genera of the Chondracanthidae, a copepod family parasitic on marine fishes. Beaufortia 229: $105-218$.

Ho J.S., Kim I.H. 1995: Acanthochondria (Copepoda: Chondracanthidae) parasitic on fishes of Sado Island in the Sea of Japan,

Received 1 October 2009 with a preliminary review of the genus. Rep. Sado Mar. Biol. Stn. Niigata Univ. 25: 45-67.

Ho J.S., KIM I.H. 1996: Copepods parasitic on fishes of Western North Pacific. Publ. Seto Mar. Biol. Lab. 37: 275-303.

Ho J.S., Kim I.H., Kumar A.B. 2000: Chondracanthid copepods parasitic on flatfishes of Kerala, India. J. Nat. Hist. 34: 709-736.

Kalman J.E. 2003: Acanthochondria hoi, a new species of parasitic copepod (Poecilostomatoida: Chondracanthidae) on the California halibut, Paralichthys californicus from Santa Monica Bay, California, with an amended key to the genus Acanthochondria. Proc. Biol. Soc. Wash. 116: 811-819.

Østergaard P., Boxshall G.A., Quicke D.L.J. 2003: Phylogeny within the Chondracanthidae (Poecilostomatoida, Copepoda). Zool. Scr. 32: 299-319.

Accepted 16 November 2009 